\title{
Prognostic Implication of Dual-Phase PET in Adenocarcinoma of the Lung
}

\author{
Mohamed Houseni ${ }^{1}$, Wichana Chamroonrat ${ }^{1,2}$, Jiyuan Zhuang ${ }^{1}$, Rohit Gopal ${ }^{1}$, Abass Alavi ${ }^{1}$, and Hongming Zhuang ${ }^{1,2}$ \\ ${ }^{1}$ Department of Radiology, Hospital of the University of Pennsylvania, University of Pennsylvania School of Medicine, Philadelphia, \\ Pennsylvania; and ${ }^{2}$ Department of Radiology, Children's Hospital of Philadelphia, University of Pennsylvania School of Medicine, \\ Philadelphia, Pennsylvania
}

The purpose of this study was to determine whether dual-phase ${ }^{18}$ F-FDG PET could be a prognostic factor for adenocarcinoma of the lung. Methods: One hundred patients with histologically proven adenocarcinoma of the lung were included in this retrospective analysis. All patients underwent dual-phase pretherapy ${ }^{18} \mathrm{~F}-\mathrm{FDG}$ PET for which, after the intravenous administration of ${ }^{18}$ F-FDG, both early ( $\left.\sim 60 \mathrm{~min}\right)$ and delayed ( $\left.~ 90 \mathrm{~min}\right)$ PET were acquired. The percentage change in the maximal standardized uptake values (SUVmax) of the cancer between the early and the delayed images was calculated. Overall survival of the SUVmax change over time together with the known prognostic factors were calculated by the Kaplan-Meier method and evaluated with the log-rank test. The prognostic significance was assessed by univariate and multivariate analyses. Results: Statistical analysis showed that SUVmax change over time between the early and the delayed PET was a strong independent predictor of outcome for lung adenocarcinoma. A cutoff of $25 \%$ change for SUVmax over time showed the best discriminative value. Patients with more than $25 \%$ increase in SUVmax had a median survival of $15 \mathrm{mo}$, compared with 39 mo for those with less than $25 \%$ increase in SUVmax. Conclusion: Dual-phase ${ }^{18} \mathrm{~F}-$ FDG PET reflects the dynamics of glucose metabolism. Our findings suggest that the percentage SUVmax change over time is a strong prognostic factor in patients with lung adenocarcinoma and can be complementary to the other well-known factors.

Key Words: dual-phase ${ }^{18} \mathrm{~F}-\mathrm{FDG}-\mathrm{PET}$; lung adenocarcinoma; survival; prognosis

J Nucl Med 2010; 51:535-542

DOI: 10.2967/jnumed.109.068643

\section{$\mathbf{L}$}

ung cancer is one of the most common malignancies in the world and a leading cause of death in Western countries. It is estimated that 215,020 patients in the United States received the diagnosis of lung cancer during 2008 and that 161,840 deaths were attributed to the disease (1). The 5-y survival rate is poor and is related to the low cure rate $(6 \%-$ $15 \%$ ), which in turn is associated with the lack of adequate

Received Jul. 21, 2009; revision accepted Jan. 5, 2010.

For correspondence or reprints contact: Hongming Zhuang, 34th St. and Civic Center Blvd., Department of Radiology, Children's Hospital of Philadelphia, Philadelphia, PA 19104.

E-mail: Zhuang@email.chop.edu

COPYRIGHT @ 2010 by the Society of Nuclear Medicine, Inc. screening measures, few patients diagnosed at an early stage of disease, and poor treatment efficacy in advanced disease (2). In recent years, the frequency of lung adenocarcinoma has increased (1). The major prognostic factors in lung cancer include tumor stage, clinical factors, pathologic indices, and genetic markers (3). Although the TNM staging system is the most common tool used by oncologists to estimate prognosis and to choose the suitable combination of therapy, it does not always give a satisfactory explanation for differences in survival. Recent advances in molecular biology explain more about different patterns of survival (4).

Lung cancer is characterized by carbohydrate metabolic derangements, which also have been identified as independent prognostic factors correlated with poor treatment response (5). These glucose metabolism derangements can be measured quantitatively in vivo by PET after the administration of ${ }^{18} \mathrm{~F}$-FDG. ${ }^{18} \mathrm{~F}$-FDG uptake in lung cancer cells has been correlated with growth rate and proliferation (6). Standardized uptake value (SUV) is the commonly used measure of ${ }^{18} \mathrm{~F}-\mathrm{FDG}$ uptake in tumors. It provides a semiquantitative and static index of ${ }^{18}$ F-FDG uptake and is conceptualized as the ratio of ${ }^{18} \mathrm{~F}-\mathrm{FDG}$ uptake in the tumor to the injection dose normalized to the patient's body weight (7).

Although malignant lesions may have higher levels of SUV, various benign conditions, such as inflammation cells or granulation tissues, may also have a high SUV (8). Because of the longer time required for levels of ${ }^{18} \mathrm{~F}-\mathrm{FDG}$ to plateau in cancer cells than in inflammatory cells in cell line studies, some investigators performed dual-phase ${ }^{18} \mathrm{~F}$ FDG PET, which includes delayed scanning, to differentiate benign from malignant lesions in various cancers. The results from most investigators showed that this delayed scan is valuable $(9,10)$. This finding probably is related to the upregulation of glucose consumption, demonstrated by the malignant cells, to obtain more energy for proliferation. This leads to graded concentration of ${ }^{18} \mathrm{~F}-\mathrm{FDG}$ in tumor cells. In contrast, such a prolonged period of ${ }^{18} \mathrm{~F}$-FDG uptake is less common in inflammatory lesions or normal tissues (10).

Although some studies correlated the SUV to survival $(11,12)$, to the best of our knowledge, the prognostic role of dual-phase ${ }^{18} \mathrm{~F}-\mathrm{FDG}$ PET in primary lung cancer has not 
been evaluated previously. The purpose of this study was to determine whether dual-phase ${ }^{18}$ F-FDG PET can predict the outcome in patients with primary lung adenocarcinoma.

\section{MATERIALS AND METHODS}

\section{Patients}

The medical records of 100 consecutive patients with newly diagnosed lung adenocarcinoma who underwent ${ }^{18} \mathrm{~F}$-FDG PET at our institution from January 2000 to January 2004 were retrospectively reviewed. Follow-up was completed and closed by the death of the last patient in August 2008. Eligibility requirements included the presence of histologic proof of adenocarcinoma and contrastenhanced chest CT and PET performed within $30 \mathrm{~d}$. Exclusion criteria were the following: known diabetes, age younger than $18 \mathrm{y}$, prior lung surgery, and chemotherapy or radiation therapy. After reviewing the available clinical information including the surgical pathology reports, initial staging was assigned according to the guidelines of the American Society of Clinical Oncology (13). This study was performed after approval had been obtained from the Institutional Review Board. Patient and tumor characteristics are listed in Table 1.

\section{${ }^{18}$ F-FDG PET}

PET was performed as a part of the initial workup of patients within $14 \mathrm{~d}$ after pathologic diagnosis of the lung cancer. All patients fasted for at least $6 \mathrm{~h}$ before examination to ensure standardized glucose metabolism. At the time of ${ }^{18} \mathrm{~F}-\mathrm{FDG}$ administration, fasting plasma glucose values were lower than $150 \mathrm{mg} / \mathrm{dL}$ in all patients. Depending on the patients' weight, an activity of $2.51 \mathrm{MBq} / \mathrm{kg}$ of ${ }^{18} \mathrm{~F}-\mathrm{FDG}$ was injected through an indwelling catheter inserted into an antecubital vein. PET scans were acquired using a dedicated full-ring scanner (CPET PET scanner; Philips/ADAC) equipped with lutetium oxyorthosilicate crystals, with a $162-\mathrm{mm}$ axial field of view.

Dual-phase ${ }^{18}$ F-FDG PET was performed for all patients, for whom an early ( $\sim 60 \mathrm{~min})$ and delayed ( $\sim 90 \mathrm{~min})$ PET study was acquired, after ${ }^{18}$ F-FDG administration. The early scan was obtained from the skull base to mid thigh, whereas the second scan was acquired from the neck to the upper abdomen. Patients were instructed not to move or leave the scanner between the two ${ }^{18} \mathrm{~F}$ FDG PET scans. Imaging was performed, using sequential overlapping scans, by acquiring 6-8 bed positions, depending on patients' heights. The acquisition time for scanning was 2 min for emission and $1 \mathrm{~min}$ for transmission per bed position. The transmission scan was acquired using a ${ }^{137} \mathrm{Cs}$ single-event source of 662 to correct for nonuniform attenuation. Patients were examined supine, with their arms above their head. The PET scanner was working in a fully 3 -dimensional mode. Image reconstruction was performed using an iterative reconstruction algorithm based on the row action maximum likelihood algorithm. The reconstructed volume image had the same number of slices and slice separation as the raw sinogram data and an image pixel size of $4.0 \mathrm{~mm}$. Resolution was $5.5 \mathrm{~mm}$ in full at half maximum at the center of the field of view. Slice thickness and the slice interval were both $4 \mathrm{~mm}$. The reconstructed images were displayed in axial, coronal, and sagittal planes and were interpreted by 2 nuclear medicine physicians. Quantitative analysis was applied to the attenuation-corrected images by calculating the SUV of areas of abnormal ${ }^{18} \mathrm{~F}-\mathrm{FDG}$ uptake, corrected for the injected dose of ${ }^{18} \mathrm{~F}$-FDG, and adjusted for

\begin{tabular}{|c|c|c|c|c|}
\hline Factor & $n$ & Percentage & Median & Range \\
\hline Age (y) & & & 71 & $32-92$ \\
\hline \multicolumn{5}{|l|}{ Sex } \\
\hline Male & 58 & $58 \%$ & & \\
\hline Female & 42 & $42 \%$ & & \\
\hline Albumin (g/dL) & & & 3.5 & $1.6-9$ \\
\hline Calcium (mmol/L) & & & 2.4 & $1.8-3.4$ \\
\hline Hemoglobin (g/dL) & & & 11.9 & $6.6-16.4$ \\
\hline Platelets $\left(\times 10^{9 / L)}\right.$ & & & 228.5 & $32-854$ \\
\hline White blood cells $\left(\times 10^{9} / \mathrm{L}\right)$ & & & 14.1 & $3.8-32.4$ \\
\hline \multicolumn{5}{|l|}{ Grading } \\
\hline Well differentiated & 12 & $12 \%$ & & \\
\hline Differentiated & 27 & $27 \%$ & & \\
\hline Poorly differentiated & 20 & $20 \%$ & & \\
\hline Undifferentiated & 15 & $15 \%$ & & \\
\hline Unknown & 26 & $26 \%$ & & \\
\hline \multicolumn{5}{|l|}{ Stage $(n=64)$} \\
\hline IA & 13 & & & \\
\hline IB & 8 & & & \\
\hline$\| A$ & 6 & & & \\
\hline IIB & 4 & & & \\
\hline IIIA & 14 & & & \\
\hline IIIB & 9 & & & \\
\hline IV & 10 & & & \\
\hline SUVmax1 & & & 5.5 & $1.7-27.1$ \\
\hline SUVmax2 & & & 7.2 & $1.8-29.9$ \\
\hline SUV change & & & $18.8 \%$ & $-28.6 \%-66.7 \%$ \\
\hline
\end{tabular}

All patients $(n=100)$ had histologically proven adenocarcinoma of the lung. 
the patient's weight, as previously described (14). Tumor mass was identified by areas of pathologically increased ${ }^{18} \mathrm{~F}-\mathrm{FDG}$ uptake, avoiding physiologic uptake. SUV was independently measured by using regions of interest drawn on the area of maximal metabolic activity on every axial slice of tumor-related increased ${ }^{18} \mathrm{~F}-\mathrm{FDG}$ uptake. SUVmax was defined as the highest pixel value related to the neoplasm burden in each study and was computed using the following formula: SUVmax = maximum activity concentration in the neoplasm $(\mathrm{kBq} / \mathrm{mL}) /[$ injected dose $(\mathrm{MBq}) /$ body weight $(\mathrm{kg})]$.

SUVmax was calculated for both the early (SUVmax1) and the delayed (SUVmax2) ${ }^{18}$ F-FDG PET scans, for which identical transaxial slices were identified by using the bed position number together with the anatomic landmarks. The percentage change of SUVmax of neoplasm between the early and delayed images was calculated as follows: percentage change SUVmax $=[($ SUVmax $2-$ SUVmax1)/SUVmax1] $\times 100 \%$.

\section{CT}

CT images were obtained with multislice CT scanners: the LightSpeed QX/i (GE Healthcare) or SOMATOM Sensation 4 (Siemens AG Medical). Scanning was done supine in the craniocaudal direction during the inspiration phase, from lung apices to below the level of the adrenal glands. Contrast enhancement with $100 \mathrm{~mL}$ of iopromide (Ultravist 300; Schering AG) was used, and volumetric CT examination of the chest was obtained. Images were reviewed using lung, mediastinal, and bone windowing.

\section{Survival Analysis}

Overall survival was the endpoint of this study. Overall survival time was calculated from the date of pathologic diagnosis of lung cancer to the date of death as a result of any cause. Details of the verification of dates of death have been described previously (15).

\section{Statistical Analysis}

Frequency distributions of selected variables were compared by Fisher exact tests. Cut points were established by means of exploring martingale residual plots and the minimum $P$ value approach.

Actuarial survival curves and probabilities were generated using the method of Kaplan and Meier. Significance of the difference between groups was assessed using the log-rank test. A multivariate model was built using Cox proportional hazards regression.

All tests were 2-sided and were performed at the 5\% level of significance by using PASW for Windows, version 18.0 (SPSS Inc.).

\section{RESULTS}

\section{Patients and Treatment}

Detailed demographic and clinical information are presented in Table 1. Patients had a median age of $71 \mathrm{y}$ (range, 32-92 y). There were 58 men and 42 women. The histologic type was adenocarcinoma in all cases. Although histology results were available for all patients, the lack of some clinical data or an inconclusive pathology report regarding the surgical margin and nodal involvement for some patients would not allow confident clinical staging. Appropriate clinical staging was achieved for 64 patients.

Surgery was performed in $42(42 \%)$ patients. The breakdown by the extent of resection was as follows: pneumonec- tomy, 2 patients; lobectomy, 24 patients; and wedge resection, 16 patients. Mediastinal lymph node dissection was performed in $35(83.3 \%)$ of the 42 patients. An additional component of rib resection was performed in 4 patients. Of the 42 patients with surgery, adjuvant therapy was administered postoperatively in 13 patients: 11 patients received radiation therapy, and 2 patients received concurrent radiation-chemotherapy. Forty-one patients received radiation therapy; $33(80.5 \%)$ of those patients underwent concurrent chemotherapy. Seventeen patients were treated with chemotherapy alone.

At the end of this investigation, there was no patient alive. The 12-, 24-, 36-, 48-, and 60-mo survival rates were $84 \%, 69 \%, 60 \%, 57 \%$, and $52.1 \%$, respectively.

\section{Tumor Characteristics}

The median size of the lung neoplasm as measured on CT images or during examination of the surgically resected specimens (if available) was $2.7 \mathrm{~cm}$ (range, $1-5.4 \mathrm{~cm}$ ). Regional lymph node involvement was pathologically investigated in 64 patients and proved to be involved in 36 patients $(56.3 \%)$ of the 64 . The presence of distant metastases was diagnosed in 10 patients $(15.6 \%)$.

\section{${ }^{18}$ F-FDG PET}

Patients had a median SUVmax1 of 5.5 (range, 1.7-27.1) and SUVmax2 of 7.2 (range, 1.8-29.9). When both values were compared, an increase in SUVmax over time was demonstrated in $90(90 \%)$ patients, with no change in 7 (7\%) and a decrease in $3(3 \%)$ patients. The median of percentage change of SUVmax was $18.8 \%$ (range, $-28.6 \%-66.7 \%$ ). The distribution of SUVmax 1 and SUV$\max 2$ and the percentage change of SUVmax over time are shown in Figure 1.

\section{Percentage Change of ${ }^{18}$ F-FDG Uptake}

The discriminative value of various cutoff percentage changes of SUVmax for the ${ }^{18}$ F-FDG uptake by the primary neoplasm was analyzed (Fig. 2). In the analysis, cutoffs at $15 \%, 20 \%, 25 \%$, and $30 \%$ showed significance, but $25 \%$ change was the most discriminative and yielded the minimum $P$ value in the log-rank test. Therefore, $25 \%$ change was used as the cutoff in this analysis.

\section{Factors Associated with Prognosis in Univariate and Multivariate Analyses}

In the univariate analysis using the Kaplan-Meier method, for which each variable was treated as a categoric variable, all factors were associated with a statistically significant correlation to the overall survival (Table 2). Clinical stage, presence of metastasis, and percentage SUVmax change (Fig. 3) showed the most significant values (log-rank overall $P=0.001,0.0005$, and 0.0002, respectively [Fig. 4]).

\section{Multivariable Regression Model}

All prognostic factors with significance in the univariate analysis were included in the multivariate model to evaluate their interaction and joint effect on the overall survival. The 

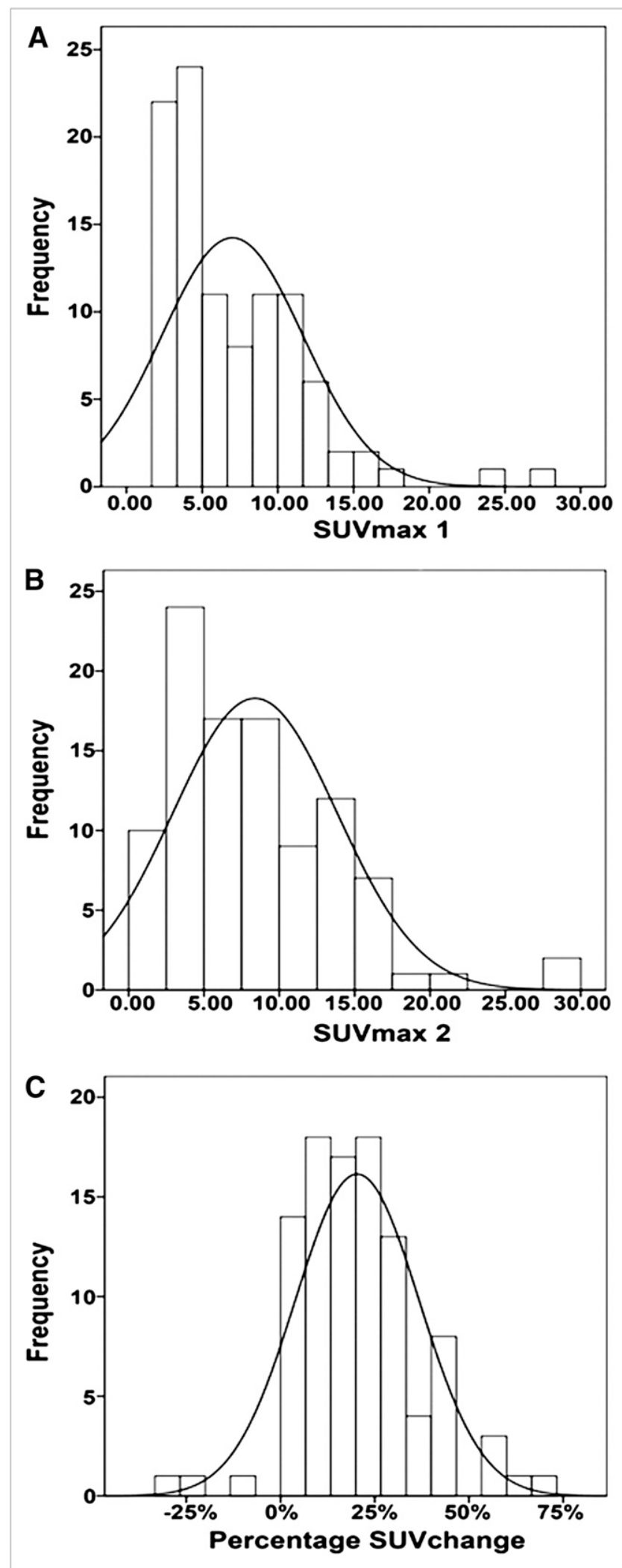

FIGURE 1. Histograms of distribution of SUVmax of tumor site on early images (A), SUVmax on delayed images (B), and percentage SUVmax change between early and delayed scans (C). Line represents gaussian fit to distribution.

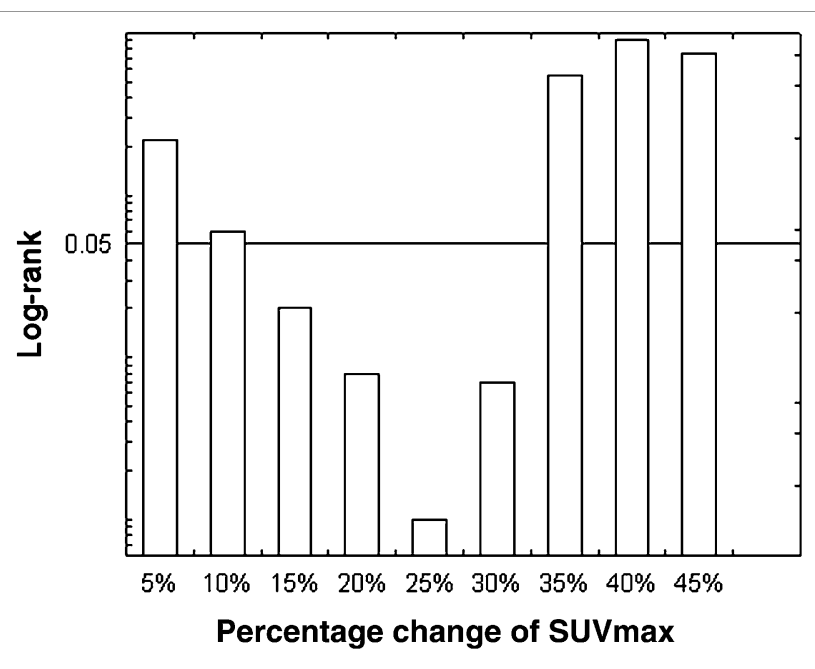

FIGURE 2. Relationship between various cutoff of percentage changes of SUVmax and their discriminative value for overall survival, as assessed by log-rank test.

adjusted Cox proportional hazards regression model revealed 4 factors to be independently correlated with the overall survival including platelet count, staging, metastatic state, and percentage SUVmax change over time. Table 3 presents the parameters and the significance of the obtained estimators.

\section{DISCUSSION}

Lung cancer remains the leading cause of cancer-related death. Validating new prognostic factors may be of value in the clinical course and management. PET quantitative methods as prognostic factors have been discussed before (16-18). However, the dynamic change in ${ }^{18} \mathrm{~F}-\mathrm{FDG}$ uptake with time, to the best of our knowledge, has not been evaluated in lung cancer as a prognostic factor. The data obtained in this study show that more than a $25 \%$ increase in SUVmax over time in primary lung cancer is a strong marker of poor prognosis in patients with lung adenocarcinoma. Patients with more than a $25 \%$ increase in SUVmax had a median survival of $15 \mathrm{mo}$, compared with 39 mo for those with less than a $25 \%$ increase in SUVmax.

We selected a percentage increase of SUVmax of $25 \%$ as the cutoff point for the analysis of prognosis because it yielded the minimum $P$ value on the log-rank test.

A variety of clinical and pathologic factors has been reported to be associated with prognosis for patients with lung cancer, such as age, sex, tumor size, lymph node and metastatic status, tumor differentiation, disease stage, and serum levels of calcium, albumin, hemoglobin, platelet and white blood cells (19-21). A univariate analysis of our data showed these factors to be, together with the percentage SUVmax change over time, significantly related to survival. However, multivariate analysis showed that, of these clinicopathologic factors, only disease stage, tumor differentiation, percentage SUVmax change over time, and 
TABLE 2. Univariate Kaplan-Meier Analysis of Overall Survival in Patients with Lung Adenocarcinoma

\begin{tabular}{|c|c|c|c|c|c|c|}
\hline Factor & $n$ & $\begin{array}{l}\text { Median } \\
\text { survival } \\
\text { (mo) }\end{array}$ & $\begin{array}{l}95 \% \text { Confidence } \\
\text { interval for } \\
\text { mean (mo) }\end{array}$ & $\begin{array}{l}\text { Hazard } \\
\text { ratio (\%) }\end{array}$ & $\begin{array}{l}\text { Cumulative } \\
\text { survival proportions } \\
\text { at } 60 \mathrm{mo}\end{array}$ & $P$ (log-rank) \\
\hline $\begin{array}{l}\text { Age }(y) \\
\quad<60 \\
\geq 60\end{array}$ & $\begin{array}{l}21 \\
79\end{array}$ & $\begin{array}{l}71 \\
26\end{array}$ & $\begin{array}{l}45-70 \\
24-33\end{array}$ & 0.36 & $\begin{array}{r}42 \\
7\end{array}$ & 0.01 \\
\hline $\begin{array}{l}\text { Sex } \\
\text { Male } \\
\text { Female }\end{array}$ & $\begin{array}{l}58 \\
42\end{array}$ & $\begin{array}{l}31 \\
22\end{array}$ & $\begin{array}{l}28-44 \\
23-38\end{array}$ & 0.84 & $\begin{array}{l}28 \\
21\end{array}$ & 0.05 \\
\hline $\begin{array}{l}\text { Albumin }(\mathrm{g} / \mathrm{dL}) \\
\quad<3.5 \\
\quad \geq 3.5 \mathrm{~L}\end{array}$ & $\begin{array}{l}26 \\
25\end{array}$ & $\begin{array}{l}26 \\
36\end{array}$ & $\begin{array}{l}17-38 \\
30-45\end{array}$ & 0.70 & $\begin{array}{l}14 \\
21\end{array}$ & 0.05 \\
\hline $\begin{array}{l}\text { Calcium }(\mathrm{mmol} / \mathrm{L}) \\
\quad<2.5 \\
\quad \geq 2.5\end{array}$ & $\begin{array}{l}45 \\
13\end{array}$ & $\begin{array}{l}38 \\
18\end{array}$ & $\begin{array}{l}33-46 \\
11-21\end{array}$ & 0.20 & $\begin{array}{r}15 \\
1\end{array}$ & 0.01 \\
\hline $\begin{array}{l}\text { Hemoglobin }(\mathrm{g} / \mathrm{dL}) \\
\quad<9 \\
\geq 9\end{array}$ & $\begin{array}{l}20 \\
45\end{array}$ & $\begin{array}{l}23 \\
35\end{array}$ & $\begin{array}{l}18-31 \\
27-49\end{array}$ & 0.71 & $\begin{array}{l}10 \\
22\end{array}$ & 0.05 \\
\hline $\begin{array}{l}\text { Platelets } \\
\qquad 160 \times 10 \mathrm{~g} / \mathrm{L} \\
\geq 160 \times 10 \% / \mathrm{L}\end{array}$ & $\begin{array}{l}14 \\
51\end{array}$ & $\begin{array}{l}18 \\
31\end{array}$ & $\begin{array}{l}11-31 \\
30-41\end{array}$ & 1.80 & $\begin{array}{l}11 \\
38\end{array}$ & 0.007 \\
\hline $\begin{array}{l}\text { White blood cells } \\
\quad<12.5 \times 10^{9 / L} \\
\geq 12.5 \times 10^{9 / L}\end{array}$ & $\begin{array}{l}24 \\
40\end{array}$ & $\begin{array}{l}32 \\
21\end{array}$ & $\begin{array}{l}26-42 \\
16-32\end{array}$ & 0.92 & $\begin{array}{r}21 \\
9\end{array}$ & 0.04 \\
\hline $\begin{array}{l}\text { Differentiation } \\
\text { Well; moderate } \\
\text { Poor }\end{array}$ & $\begin{array}{l}39 \\
20\end{array}$ & $\begin{array}{r}28 \\
9\end{array}$ & $\begin{array}{r}19-35 \\
6-24\end{array}$ & 0.63 & $\begin{array}{r}12 \\
5\end{array}$ & 0.04 \\
\hline $\begin{array}{l}\text { Staging } \\
\text { I-II } \\
\text { III-IV }\end{array}$ & $\begin{array}{l}33 \\
31\end{array}$ & $\begin{array}{l}39 \\
24\end{array}$ & $\begin{array}{l}33-45 \\
18-31\end{array}$ & 0.46 & $\begin{array}{c}18 \\
\text { Zero }\end{array}$ & 0.001 \\
\hline $\begin{array}{l}\text { Size }(\mathrm{cm}) \\
\quad<3 \\
\quad \geq 3\end{array}$ & $\begin{array}{l}56 \\
44\end{array}$ & $\begin{array}{l}41 \\
19\end{array}$ & $\begin{array}{l}35-54 \\
16-32\end{array}$ & 2.01 & $\begin{array}{r}35 \\
9\end{array}$ & 0.01 \\
\hline $\begin{array}{l}\text { Lymph node } \\
\text { No } \\
\text { Yes }\end{array}$ & $\begin{array}{l}30 \\
34\end{array}$ & $\begin{array}{l}41 \\
19\end{array}$ & $\begin{array}{l}31-54 \\
17-28\end{array}$ & 0.40 & $\begin{array}{r}33 \\
6\end{array}$ & 0.02 \\
\hline $\begin{array}{l}\text { Metastasis } \\
\text { No } \\
\text { Yes }\end{array}$ & $\begin{array}{l}54 \\
10\end{array}$ & $\begin{array}{l}37 \\
15\end{array}$ & $\begin{array}{l}34-48 \\
11-27\end{array}$ & 0.42 & $\begin{array}{r}41 \\
6\end{array}$ & 0.0005 \\
\hline $\begin{array}{l}\text { SUVmax1 } \\
\quad<10 \\
\quad \geq 10\end{array}$ & $\begin{array}{l}78 \\
22\end{array}$ & $\begin{array}{l}31 \\
20\end{array}$ & $\begin{array}{l}28-48 \\
13-27\end{array}$ & 0.62 & $\begin{array}{l}26 \\
17\end{array}$ & 0.04 \\
\hline $\begin{array}{l}\text { SUVmax2 } \\
\quad<10 \\
\quad \geq 10\end{array}$ & $\begin{array}{l}83 \\
17\end{array}$ & $\begin{array}{l}33 \\
19\end{array}$ & $\begin{array}{l}31-45 \\
11-21\end{array}$ & 0.68 & $\begin{array}{l}21 \\
17\end{array}$ & 0.05 \\
\hline $\begin{array}{l}\text { SUVmax change } \\
\quad<25 \% \\
\geq 25 \%\end{array}$ & $\begin{array}{l}64 \\
36\end{array}$ & $\begin{array}{l}39 \\
15\end{array}$ & $\begin{array}{l}35-50 \\
12-28\end{array}$ & 0.40 & $\begin{array}{r}27 \\
6\end{array}$ & 0.0002 \\
\hline
\end{tabular}

platelet count were associated with survival. The clinicopathologic results are in agreement with other studies (2224).

The point estimates in the multivariable Cox proportional hazards model suggest that percentage change in SUVmax over time may be as significant as common clinical parameters, including staging, metastatic status, and platelet count.

In our study, analyzing SUVmax and exact executions of the protocols revealed high reproducibility. Furthermore, the current analysis of SUVmax uptake in the initial diagnosis and its change over time could be associated with the neoplasm aggressiveness. Malignant tumors are character- ized by progressive growth (25). Haberkorn et al. studied 2 groups with low and high ${ }^{18} \mathrm{~F}-\mathrm{FDG}$ uptake. In the group with high ${ }^{18} \mathrm{~F}-\mathrm{FDG}$ uptake, the degree of ${ }^{18} \mathrm{~F}-\mathrm{FDG}$ accumulation was correlated significantly with the proliferation rate (26). A positive correlation seen between ${ }^{18} \mathrm{~F}$-FDG uptake and the fraction of proliferating cells in human neoplasms more likely reflects the aggressiveness of tumors, which is correlated secondarily with the proliferative activity (27).

Dual-phase ${ }^{18} \mathrm{~F}$-FDG PET has been used to improve the diagnostic efficacy and to differentiate benign from malignant lesions (28-30). Although many theories have explained 

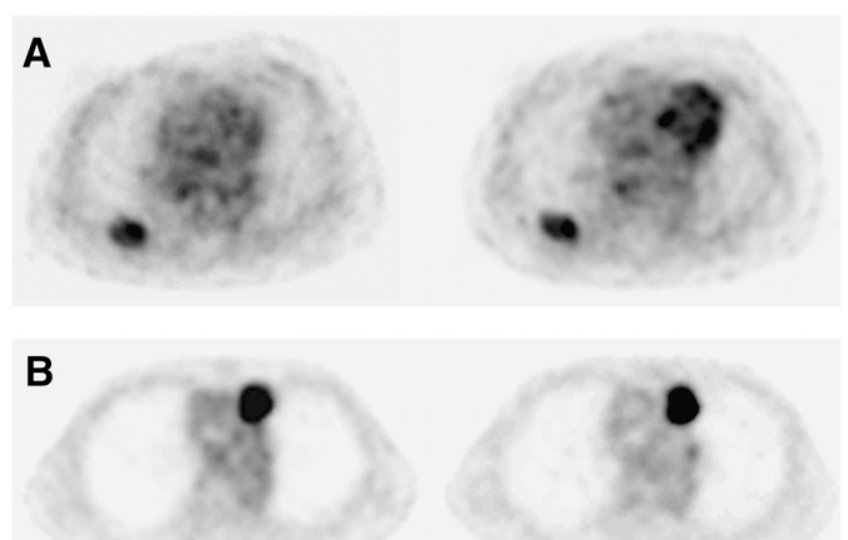

FIGURE 3. Transaxial PET images of 2 patients at early (left) and delayed (right) scans. Histopathology, in both cases, was moderately differentiated adenocarcinoma. Percentage change of SUVmax, between early and delayed scans, measures $4.3 \%$ for patient in $A$ and $36.4 \%$ for patient in B. Survival for patient in A was $28 \mathrm{mo}$, and for patient in B it was $12 \mathrm{mo}$.

the mechanism of ${ }^{18} \mathrm{~F}$-FDG uptake by tumors and its accumulation over time, the molecular basis of ${ }^{18} \mathrm{~F}-\mathrm{FDG}$ uptake is still under investigation. These theories include high glycolytic enzyme activities in both the transmembrane glucose transporter protein (particularly glucose transporter protein-1) and the cytosol (particularly hexokinase-II) and also by underexpression of glucose-6-phosphatase (31). Higashi et al. suggested that ${ }^{18} \mathrm{~F}-\mathrm{FDG}$ accumulation on delayed PET is related to hexokinase-II expression and could indicate the phosphorylation rate (9). Demura et al. reported a positive correlation in dual-time-point change with the degree of cellular differentiation in patients with lung cancers (32). A stable or decrease in ${ }^{18} \mathrm{~F}-\mathrm{FDG}$ uptake over time has been noted in 10 patients in this study. In theory, this can be due to degree of tumor differentiation and the cellular composition of neoplasms.

The significance of assessing SUVmax in a single time point in primary lesions has been wildly debated. Hoang et al. showed no correlation between survival and SUVmax. However, their study group was limited to patients with advanced non-small cell lung cancer (33). Vesselle et al. in another study revealed no prognostic information of ${ }^{18} \mathrm{~F}$ FDG uptake by lung cancer. Vesselle et al. included patients with non-small cell lung cancer of different histology (34). On the other hand, several studies reported a significant correlation between ${ }^{18} \mathrm{~F}$-FDG uptake and prognosis $(12,35)$. However, these studies have been criticized with overestimation in the statistical significance due to the failure to account for the effects of multiple testing (36). We believe that measuring percentage change in SUVmax overcomes many of factors limiting SUV measurements. These limitations include blood glucose levels, body weight, and partialvolume effect (37). Furthermore, differences in the ${ }^{18} \mathrm{~F}-\mathrm{FDG}$ dose, time of scanning, reconstruction algorithms, filters,
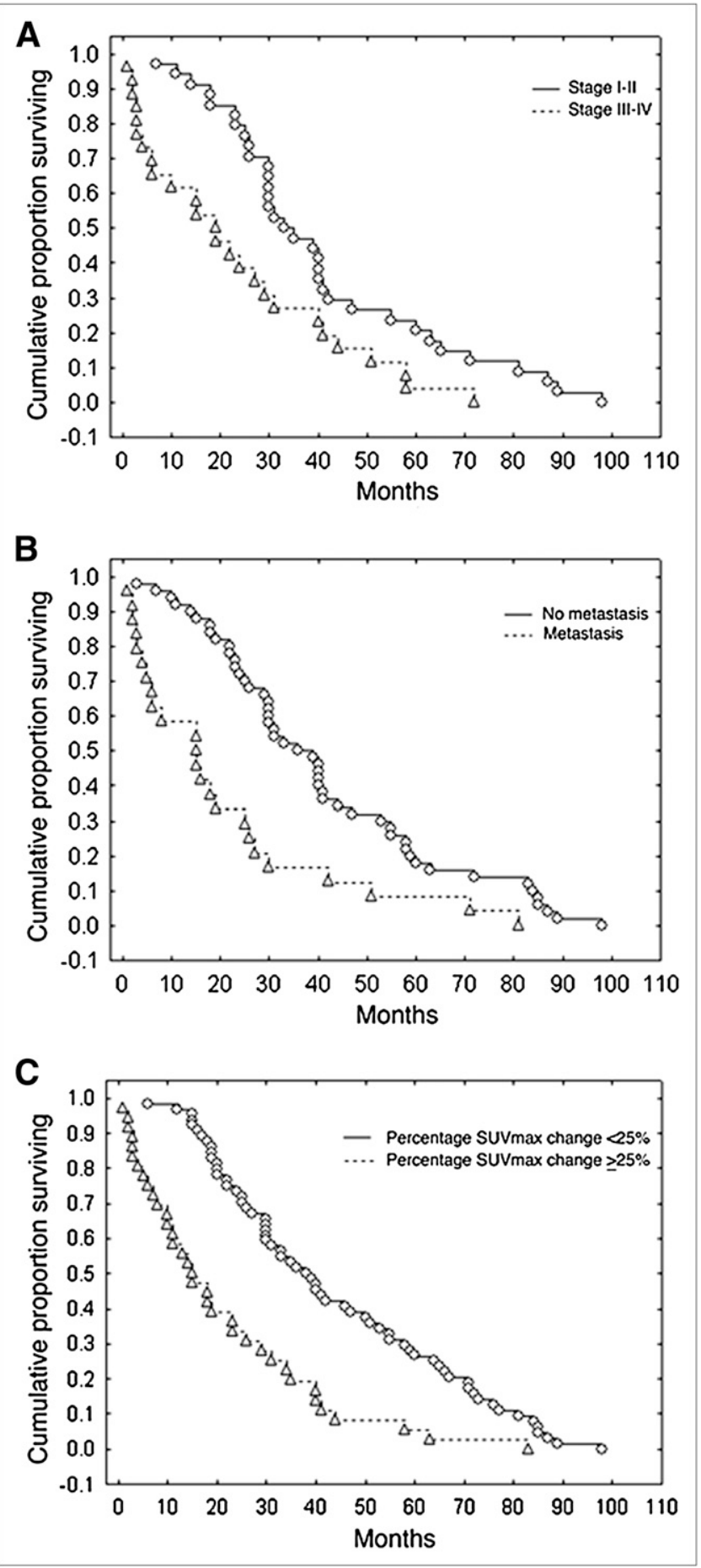

FIGURE 4. Kaplan-Meier survival plots of patients with adenocarcinoma of lung by clinical stage (stages I-II, compared with stages III-IV, $P=0.001)(A)$, presence of metastasis $(P=0.0005)(B)$, and percentage change of SUVmax (dichotomized using value of $25 \%, P=0.0002$ ) (C).

scanner characteristics, sinogram noise, and quantification methods might lead to (structural) interinstitutional SUV differences when depending on single SUV measurements (38). Thus, we proposed that measuring SUVmax change 
TABLE 3. Multivariate Cox Regression Analysis of

Overall Survival in Patients with Lung Adenocarcinoma

\begin{tabular}{|lcccc}
\hline \multicolumn{1}{|c}{ Factor } & $\begin{array}{c}\text { Relative } \\
\text { risk }^{*}\end{array}$ & $\begin{array}{c}\text { 95\% Confidence } \\
\text { interval }\end{array}$ & SE & $P$ \\
\hline Platelets & 1.15 & $1.42-2.04$ & 0.39 & 0.05 \\
\hline Staging & 2.15 & $1.63-2.83$ & 0.58 & 0.04 \\
\hline Metastasis & 1.32 & $1.04-1.53$ & 0.43 & 0.02 \\
\hline Percentage & 1.52 & $1.14-1.90$ & 0.32 & 0.01 \\
\hline SUVmax change & & & & \\
\hline
\end{tabular}

${ }^{*}$ Relative risk values are calculated at 60 mo.

over time is more feasible and reproducible than depending on single SUV detection.

The known ${ }^{18} \mathrm{~F}-\mathrm{FDG}$ PET limitations in lung cancer including false-negative results due to small-sized tumors and bronchoalveolar type of lung cancer (39) were not encountered in our study.

Several investigators have speculated that SUV is correlated with cellular proliferation or biologic factors and may be related to the metastatic potential of the tumor $(9,40)$. Our analysis indicated that patients with metastases showed slightly higher percentage SUVmax changes over time than patients without metastases. The differences did not reach a significant level in our study, maybe because of the small number of cases with metastases. Further studies with larger number of patients may clear up this point.

A limitation in our study was maintaining the exact time interval for rescanning the lung. However, taking into consideration that the average time was 30 min with \pm 6 min variability and our focus on the percentage change in SUVmax, we believe that the effect was limited. Moreover, the patient selection was based on a ${ }^{18} \mathrm{~F}$-FDG PET database; therefore, prognostic factors not directly related to ${ }^{18} \mathrm{~F}-\mathrm{FDG}$ PET may suffer from selection bias. Another limitation was the fact that some patients did not undergo extensive surgical sampling. In addition, the survival data were calculated on the basis of date of death as a result of any cause, which inevitably included a few patients who died of other reasons. It is conceivable that the result would be even better if the cause of death could have been limited to the lung cancer, and such analysis should be performed in future analyses, if possible. Finally, because this was a retrospective investigation, we could analyze only the data from previous studies, which were all done with the $60-$ and 90 -min protocols. The 60- and 90-min protocols were initially used simply because we tried to reduce the possible patient movement between the scans as much as possible so that early and delayed images could be easily compared. However, because we never had the chance to try other protocols, the results obtained from time points other than the 60 and 90 min of PET might be slightly different from our results. A prospective study on a larger scale should be conducted to ensure better control of all the factors and to avoid possible overestimation of the prognostic factors.

\section{CONCLUSION}

Percentage SUVmax change over time in a pretherapy ${ }^{18} \mathrm{~F}$ FDG PET scan is a strong predictor of mortality in patients with lung adenocarcinoma. This predictor proved to be powerful on univariate analysis and independent on the Cox regression model. Therefore, we anticipate that dualphase ${ }^{18} \mathrm{~F}$-FDG PET with measurement of the percentage SUVmax change may significantly affect the management of patients with lung adenocarcinoma and could be complementary to other well-known factors. These results remain to be confirmed in a larger prospective study.

\section{REFERENCES}

1. Jemal A, Siegel R, Ward E, et al. Cancer statistics, 2008. CA Cancer J Clin. 2008;58:71-96.

2. Camps C, Sirera R, Bremnes R, et al. Is there a prognostic role of K-ras point mutations in the serum of patients with advanced non-small cell lung cancer? Lung Cancer. 2005;50:339-346.

3. Blackstock AW, Herndon JE, 2nd, Paskett ED, et al. Similar outcomes between African American and non-African American patients with extensive-stage small-cell lung carcinoma: report from the Cancer and Leukemia Group B. $J$ Clin Oncol. 2006;24:407-412.

4. Haugen A. Molecular biology in the diagnosis of lung cancer [in Norwegian]. Tidsskr Nor Laegeforen. 2005;125:3283-3285.

5. Stanley KE. Prognostic factors for survival in patients with inoperable lung cancer. J Natl Cancer Inst. 1980;65:25-32.

6. Nelson CA, Wang JQ, Leav I, Crane PD. The interaction among glucose transport, hexokinase, and glucose-6-phosphatase with respect to ${ }^{3} \mathrm{H}-2$ deoxyglucose retention in murine tumor models. Nucl Med Biol. 1996;23:533541.

7. Sanghera B, Wong WL, Lodge MA, et al. Potential novel application of dual time point SUV measurements as a predictor of survival in head and neck cancer. Nucl Med Commun. 2005;26:861-867.

8. Zhuang H, Alavi A. 18-Fluorodeoxyglucose positron emission tomographic imaging in the detection and monitoring of infection and inflammation. Semin Nucl Med. 2002;32:47-59.

9. Higashi T, Saga T, Nakamoto Y, et al. Relationship between retention index in dual-phase ${ }^{18} \mathrm{~F}-\mathrm{FDG}$ PET, and hexokinase-II and glucose transporter-1 expression in pancreatic cancer. J Nucl Med. 2002;43:173-180.

10. Zhuang H, Pourdehnad M, Lambright ES, et al. Dual time point ${ }^{18} \mathrm{~F}$-FDG PET imaging for differentiating malignant from inflammatory processes. $\mathrm{J} \mathrm{Nucl} \mathrm{Med}$. 2001;42:1412-1417.

11. Borst GR, Belderbos JS, Boellaard R, et al. Standardised FDG uptake: a prognostic factor for inoperable non-small cell lung cancer. Eur J Cancer. 2005;41:1533-1541.

12. Sasaki R, Komaki R, Macapinlac H, et al. $\left[{ }^{18} \mathrm{~F}\right]$ fluorodeoxyglucose uptake by positron emission tomography predicts outcome of non-small-cell lung cancer. J Clin Oncol. 2005;23:1136-1143.

13. Clinical practice guidelines for the treatment of unresectable non-small-cell lung cancer: adopted on May 16, 1997 by the American Society of Clinical Oncology. J Clin Oncol. 1997;15:2996-3018.

14. Weber WA. Use of PET for monitoring cancer therapy and for predicting outcome. J Nucl Med. 2005;46:983-995.

15. Zhou W, Suk R, Liu G, et al. Vitamin D is associated with improved survival in early-stage non-small cell lung cancer patients. Cancer Epidemiol Biomarkers Prev. 2005; 14:2303-2309.

16. Berghmans T, Dusart M, Paesmans M, et al. Primary tumor standardized uptake value (SUVmax) measured on fluorodeoxyglucose positron emission tomography (FDG-PET) is of prognostic value for survival in non-small cell lung cancer (NSCLC): a systematic review and meta-analysis (MA) by the European Lung Cancer Working Party for the IASLC Lung Cancer Staging Project. $J$ Thorac Oncol. 2008;3:6-12.

17. Downey RJ, Akhurst T, Gonen M, et al. Preoperative F-18 fluorodeoxyglucosepositron emission tomography maximal standardized uptake value predicts survival after lung cancer resection. J Clin Oncol. 2004;22:3255-3260.

18. Gallamini A, Hutchings M, Rigacci L, et al. Early interim $2-\left[{ }^{18} \mathrm{~F}\right]$ fluoro-2-deoxyD-glucose positron emission tomography is prognostically superior to international prognostic score in advanced-stage Hodgkin's lymphoma: a report from a joint Italian-Danish study. J Clin Oncol. 2007;25:3746-3752. 
19. Lyons G, Quadrelli S, Silva C, et al. Analysis of survival in 400 surgically resected non-small cell lung carcinomas: towards a redefinition of the $\mathrm{T}$ factor. J Thorac Oncol. 2008;3:989-993.

20. Asmis TR, Ding K, Seymour L, et al. Age and comorbidity as independent prognostic factors in the treatment of non small-cell lung cancer: a review of National Cancer Institute of Canada Clinical Trials Group trials. J Clin Oncol. 2008;26:54-59.

21. Strand TE, Rostad H, Moller B, Norstein J. Survival after resection for primary lung cancer: a population based study of 3211 resected patients. Thorax. 2006;61:710-715.

22. Varlotto JM, Flickinger JC, Recht A, Nikolov MC, DeCamp MM. A comparison of survival and disease-specific survival in surgically resected, lymph nodepositive bronchioloalveolar carcinoma versus nonsmall cell lung cancer: implications for adjuvant therapy. Cancer. 2008;112:1547-1554.

23. Hoekstra CJ, Stroobants SG, Smit EF, et al. Prognostic relevance of response evaluation using $\left[{ }^{18} \mathrm{~F}\right]$-2-fluoro-2-deoxy-D-glucose positron emission tomography in patients with locally advanced non-small-cell lung cancer. J Clin Oncol. 2005;23:8362-8370.

24. Zhou W, Heist RS, Liu G, et al. Circulating 25-hydroxyvitamin D levels predict survival in early-stage non-small-cell lung cancer patients. J Clin Oncol. 2007;25:479-485.

25. Keshgegian AA, Cnaan A. Proliferation markers in breast carcinoma: mitotic figure count, S-phase fraction, proliferating cell nuclear antigen, Ki-67 and MIB1. Am J Clin Pathol. 1995;104:42-49.

26. Haberkorn U, Strauss LG, Reisser C, et al. Glucose uptake, perfusion, and cell proliferation in head and neck tumors: relation of positron emission tomography to flow cytometry. J Nucl Med. 1991;32:1548-1555.

27. Tsujikawa T, Otsuka H, Morita N, et al. Does partial volume corrected maximum SUV based on count recovery coefficient in 3D-PET/CT correlate with clinical aggressiveness of non-Hodgkin's lymphoma? Ann Nucl Med. 2008;22:23-30.

28. Kubota K, Itoh M, Ozaki K, et al. Advantage of delayed whole-body FDG-PET imaging for tumour detection. Eur J Nucl Med. 2001;28:696-703.

29. Xiu Y, Bhutani C, Dhurairaj T, et al. Dual-time point FDG PET imaging in the evaluation of pulmonary nodules with minimally increased metabolic activity. Clin Nucl Med. 2007;32:101-105.
30. Shinya T, Rai K, Okumura Y, et al. Dual-time-point F-18 FDG PET/CT for evaluation of intrathoracic lymph nodes in patients with non-small cell lung cancer. Clin Nucl Med. 2009;34:216-221.

31. Zhao S, Kuge Y, Mochizuki T, et al. Biologic correlates of intratumoral heterogeneity in ${ }^{18}$ F-FDG distribution with regional expression of glucose transporters and hexokinase-II in experimental tumor. J Nucl Med. 2005;46:675682.

32. Demura Y, Tsuchida T, Ishizaki T, et al. ${ }^{18} \mathrm{~F}-\mathrm{FDG}$ accumulation with PET for differentiation between benign and malignant lesions in the thorax. J Nucl Med. 2003;44:540-548

33. Hoang JK, Hoagland LF, Coleman RE, Coan AD, Herndon JE, II, Patz EF Jr. Prognostic value of fluorine-18 fluorodeoxyglucose positron emission tomography imaging in patients with advanced-stage non-small-cell lung carcinoma. J Clin Oncol. 2008;26:1459-1464.

34. Vesselle H, Freeman JD, Wiens L, et al. Fluorodeoxyglucose uptake of primary non-small cell lung cancer at positron emission tomography: new contrary data on prognostic role. Clin Cancer Res. 2007;13:3255-3263.

35. Hellwig D, Groschel A, Graeter TP, et al. Diagnostic performance and prognostic impact of FDG-PET in suspected recurrence of surgically treated non-small cell lung cancer. Eur J Nucl Med Mol Imaging. 2006;33:13-21.

36. Atkins CD. Overestimation of the prognostic significance of SUV measurement by positron emission tomography for non-small-cell lung cancer. J Clin Oncol. 2005;23:6799-6800.

37. Keyes JW Jr. SUV: standard uptake or silly useless value? J Nucl Med. 1995; 36:1836-1839.

38. Boellaard R, Krak NC, Hoekstra OS, Lammertsma AA. Effects of noise, image resolution, and ROI definition on the accuracy of standard uptake values: a simulation study. J Nucl Med. 2004;45:1519-1527.

39. Hellwig D, Ukena D, Paulsen F, Bamberg M, Kirsch CM. Pneumologie. 2001;55:367-377.

40. Yen TC, Chang YC, Chan SC, et al. Are dual-phase ${ }^{18}$ F-FDG PET scans necessary in nasopharyngeal carcinoma to assess the primary tumour and locoregional nodes? Eur J Nucl Med Mol Imaging. 2005;32:541-548. 